\title{
Study on Dynamic Change of Land Use in Qingzhen City Based on GIS Technology and CA-Markov Model
}

\author{
Yi Bai ${ }^{1,2}$, Song $\mathrm{Li}^{1,2^{*}}$, Qianqin Zuo ${ }^{1}$, Wei Zhang ${ }^{1}$ \\ ${ }^{1}$ School of Geography and Resources, Guizhou Education University,Guiyang 550018,China \\ ${ }^{2}$ Guizhou Provincial Key Laboratory of Geographic State Monitoring of Watershed,Guiyang 550018, China
}

\begin{abstract}
With the rapid development of social economy, the sustainable use of land is becoming more and more important. Based on GIS and remote sensing technology, the work processed the land use status data of Qingzhen in 2016 and 2020, obtained the dynamic change data during the period, analyzed its land use structure, quantity and degree. Finally, we used the CA-Markov model to obtain the flow direction and probability of land use type. Results showed that the rate of non-agricultural land increase, and the rate of other land reduce. Suggestions :(1) centralization of land resources and integration of urban and rural development.(2) Continue to develop characteristic industries and create new business cards for the city.(3) Pay attention to the quality of cultivated land and rationally develop unused land.
\end{abstract}

\section{Introduction}

The sustainable use of land is one of the most frequently stated problems with the rapid growth of economy. In order to ensure the sustainable development of land resources, both qualitative and quantitative methods are used to analyze land use and to take positive measures. By using $3 \mathrm{~S}$ technology to establish the dynamic monitoring system of land use, the land use status can be obtained, the land use plan can be formulated, and the intensive use of land can be realized [1-3]. CA-Markov model can simulate land cover change quite well. Ramezani, for example, used Landsat satellite images and CA-Markov prediction models to study simulated land use/cover change prediction in the North Khorasan region of Iran [4]. Markov models are used to dynamically monitor and predict land use changes [5].

In this study, the remote sensing image data of Qingzhen in 2016 and 2020 were used to extract information about land use changes, and the quantity, structure, degree and conversion type of monitoring results were analyzed, to provide valuable suggestions and countermeasures for the sustainable use of land in Qingzhen. Through spatial prediction research of land use in 2024, it is expected to provide valuable protection for sustainable development.

\section{Research Methods and Data Sources}

\subsection{Data sources}

This study area is located at west of Guiyang, and coordinates of latitude and longitud are $106^{\circ} 07^{\prime} E$ to $106^{\circ} 33^{\prime} E, 26^{\circ} 21^{\prime} N$ to $26,59^{\prime} N$, respectively. The area of this study area is $1386.6 \mathrm{~km}^{2}$. Land use data for 2016 were obtained by Qingzhen Natural Resources Bureau, and the main image data for 2020 was Landsat8 TM, by Geographic Data Cloud. The 2020 change data is updated on the 2016 land use data based on image texture and the third national land survey data.

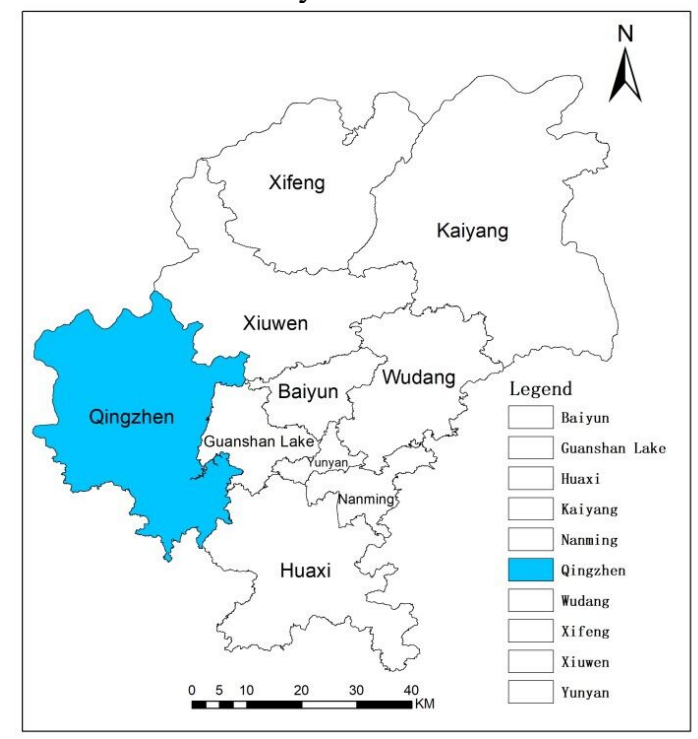

Fig 1. Study area and its location map

\subsection{Research methods}

For discovering and extracting information about land use change, the dynamic degree is used to analyze the quantity, degree and rate of land change. the transfer matrix and CA-Markov model are used to analyze and predict the land flow direction.

Single land-use dynamics, refers to the extent to which land-use types change within the same scope of study,

*Corresponding author: baiyigznc@foxmail.com 
then determining the extent of change in this type of land use. The variable $K$ is expressed as follows:

$$
K=\frac{U_{b}-U_{a}}{U_{A}} \times \frac{1}{T} \times 100 \%
$$

$K$ represents the dynamic degree of a land use type in the research time, $T$ represents is the research time, $U_{a}$ and $U_{b}$ is the number of a land use type in the early and late stages of the study, respectively.

(2) Comprehensive dynamics

$$
L_{c}=\frac{\sum_{i=1}^{n} \Delta L U_{i-j}}{2 \sum_{i-1}^{n} L U_{I}} \times \frac{1}{T} \times 100 \%
$$

$T$ represents the duration of the study, $L_{c}$ represents the comprehensive land use dynamic degree, $L U_{i}$ is the i type of land area in the preliminary study, $\Delta L U_{i-j}$ is the area of the land type conversion from $i$ to $j$ during the research

(1)Land - use transfer probability matrix

It represents probability in the process of state transfer. CA-Markov model state transition matrix formula is:

$$
P=P_{(p q)}=\left[\begin{array}{cccc}
P_{(11)} & P_{(12)} & \cdots & P_{(1 n)} \\
P_{(21)} & P_{(22)} & \cdots & P_{(2 n)} \\
\vdots & \vdots & \ddots & \vdots \\
P_{(n 1)} & P_{(n 2)} & \cdots & P_{(n n)}
\end{array}\right]
$$

$P_{(p q)}$ represents the transformation probability from $p$ class to $q$ class, is land use type, the value range of $P_{(p q)}$ is between 0 and 1 .

Formulae for predicting future land changes(CAMarkov model):

CA-Markov model predicting future land changes formula is:

$$
X_{T+1}=P(i j) \times X_{T}
$$

$X_{T+1}$ is the status of land use systems in $T+1$ moment, $X_{T}$ is the status of land use systems in $T$ moment, $P_{(i j)}$ is the state transition matrix.

\section{Results and analysis}

\subsection{Image processing}

Processing image by the ERDAS software, the boundary line of the vector administrative region of Qingzhen city is combined with the single-band image which needs to be fused, then the remote sensing image map of Qingzhen in 2016 and 2020 is obtained respectively.

According to the natural environment characteristics of the study area, the remote sensing image are interpretated by spectral characteristics, texture features, geographical location, imaging time, etc[6]. Because there are wetlands near Hongfeng Lake and other lakes in Qingzhen, referring to the Classification table of the third National Land Survey, it's divided into 13 species.

Take $\boldsymbol{W L}$ to represent Wetland, $\boldsymbol{A} \boldsymbol{L}$ to represent Arable Land, $\boldsymbol{P} \boldsymbol{L}$ to represent Plantation Land, $\boldsymbol{W D L}$ to represent Woodland, $\boldsymbol{M D}$ to For Meadows, $\boldsymbol{C S L}$ to represent Commercial Services Land, IML to represent Industrial and Mining Land, $\boldsymbol{R} \boldsymbol{L}$ to represent Residential Land,
PMPL to represent land for Public Management and Public Service Land, $\boldsymbol{S} \boldsymbol{L}$ to represent Special Land, $\boldsymbol{T} \boldsymbol{L}$ to represent Transport Land, $\boldsymbol{W W F L}$ to represent Water and Water Facilities Land, $\boldsymbol{O L}$ to represent Other Lands.

After remote sensing image processing and interpreting, the land-use and land-cover change are obtained as follows:

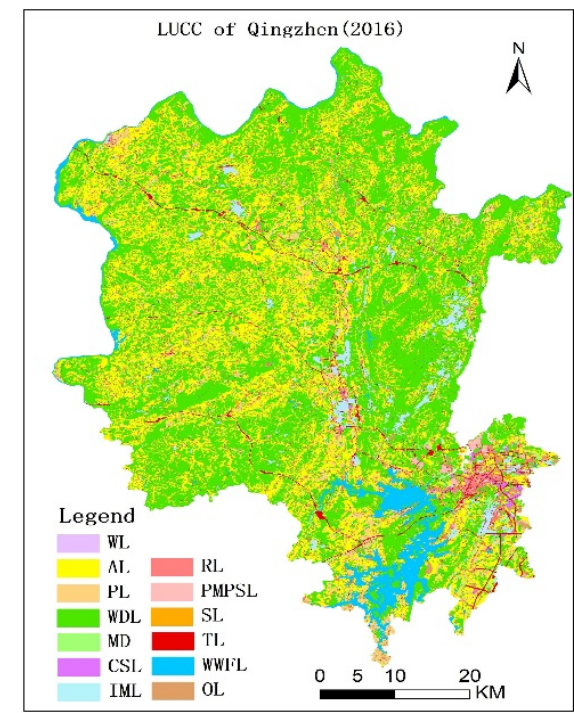

Fig 2. LUCC of Qingzhen (2016).

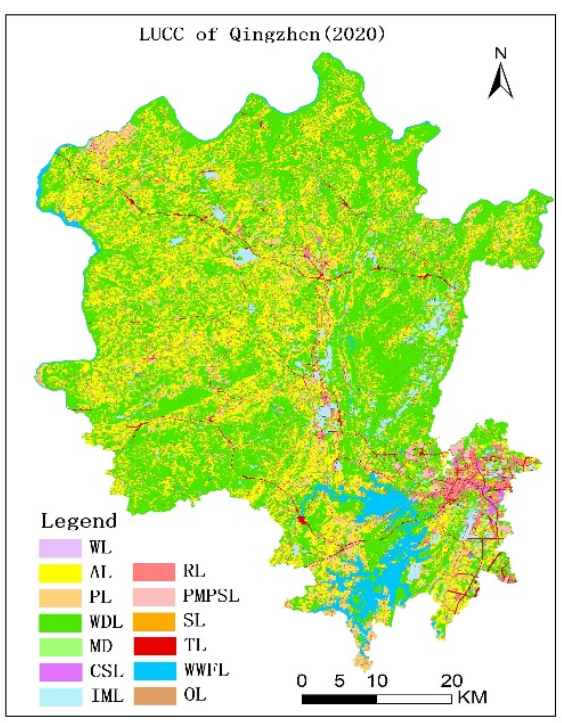

Fig 3. LUCC of Qingzhen (2020).

\subsection{Land use change rate analysis}

\subsubsection{Single dynamic analysis}

To get a better idea of which kind of dynamic degree, according to the specific situation of the study area, some of the land classes are temporarily combined into seven categories. According to formula (1), the calculation results of single land use dynamic degree were calculated as shown in Table 1. 
Table1. Single land use dynamics in Qingzhen (20162020)

\begin{tabular}{cccc}
\hline Land lasses & $\mathbf{K}(\%)$ & Land classes & K(\%) \\
\hline Wetlands & 6.93 & $\begin{array}{c}\text { Construction } \\
\text { land }\end{array}$ & 3.25 \\
$\begin{array}{c}\text { Agricultural } \\
\text { land }\end{array}$ & -0.54 & Water Area & -0.26 \\
Forilities & -10.53 \\
Grassland & 0.05 & Other land & \\
\hline
\end{tabular}

As can be seen from Table 1, the dynamic degree of other land and grassland are negative and change greatly, indicating that these two types of land decrease faster. The most negative dynamic degree is other land, with $10.53 \%$ of other land being exploited between 2016 and 2020; $6.53 \%$ of grassland used for other purposes; less negative changes of dynamic degree are agricultural land and water facility land, both types of land being reduced more slowly, and positive values of dynamic degree are construction land, wetlands and woodlands, indicating an increase in the three types of land, which may be due to the advancement of urbanization. The growth of woodland and wetland may be caused by the expansion of the definition of wetland on the one hand, and on the other hand, it also shows that Qingzhen pays attention to the protection of green ecology.

\subsubsection{Comprehensive dynamics}

Calculated by formula (2), the dynamic degree of comprehensive land use in Qingzhen City for 4 years (2016-2020) is $0.6 \%$, less than $1 \%$, which indicates that the overall change rate is not intense in this years, and the balance of occupation and compensation is basically achieved.

\subsection{Land use probability transfer Prediction}

\subsection{1 land use Markov projections}

Using IDRISI software to convert the vector data from 2016 to 2020 into 30/30 raster data, select the CA-Markov model to calculate the probability matrix of land use transfer, the row represents the probability of land outflow, and the rank represents the probability of land inflow. As shown in Table 2, the prediction of land conversion probability can be clearly obtained.

Table2. Land Probability matrix of land use transfer (\%)

\begin{tabular}{cccccccccccccc}
\hline & $\boldsymbol{W L}$ & $\boldsymbol{A L}$ & $\boldsymbol{P L}$ & $\boldsymbol{W D L}$ & $\boldsymbol{M D}$ & $\boldsymbol{C S L}$ & $\boldsymbol{I M L}$ & $\boldsymbol{R L}$ & $\boldsymbol{P M P L}$ & $\boldsymbol{S L}$ & $\boldsymbol{T L}$ & $\boldsymbol{W W F}$ & $\boldsymbol{O L}$ \\
\hline $\boldsymbol{W L}$ & 0.41 & 22.8 & 10.32 & 39.36 & 0.24 & 0.48 & 2.4 & 4.8 & 0.72 & 0 & 3.6 & 14.4 & 0.48 \\
$\boldsymbol{A L}$ & 0.02 & 29.4 & 6.02 & 55.6 & 0.11 & 0.05 & 1.01 & 2.67 & 0.18 & 0.01 & 2.73 & 1.92 & 0.27 \\
$\boldsymbol{P L}$ & 0.14 & 32.21 & 5.21 & 47.41 & 0.36 & 0.41 & 2.58 & 3.49 & 0.63 & 0.08 & 2.98 & 4.1 & 0.41 \\
$\boldsymbol{W D L}$ & 0.01 & 39.44 & 6.5 & 45.17 & 0.1 & 0.06 & 0.66 & 3.07 & 0.22 & 0.02 & 2.42 & 2.06 & 0.27 \\
$\boldsymbol{M D}$ & 0.37 & 27.83 & 5.13 & 45.31 & 0.54 & 0.29 & 2.72 & 3.97 & 1.68 & 0.12 & 4.34 & 7.59 & 0.12 \\
$\boldsymbol{C S L}$ & 0.04 & 25.09 & 5.8 & 38 & 0.94 & 1.63 & 3.08 & 6.74 & 1.99 & 0.04 & 5.19 & 11.06 & 0.4 \\
$\boldsymbol{I M L}$ & 0.05 & 29.93 & 4.5 & 50.87 & 0.41 & 0.33 & 2.99 & 3.77 & 0.63 & 0.06 & 3.34 & 2.75 & 0.37 \\
$\boldsymbol{R I}$ & 0.06 & 30.25 & 4.63 & 46.91 & 0.7 & 0.79 & 2.71 & 3.71 & 1.22 & 0.09 & 3.4 & 5.21 & 0.33 \\
$\boldsymbol{P M P L}$ & 0.04 & 27.8 & 4.14 & 46.92 & 0.91 & 1.45 & 1.91 & 5.53 & 1.79 & 0.09 & 4.78 & 4.27 & 0.39 \\
$\boldsymbol{S L}$ & 0.12 & 24.71 & 3.07 & 55.44 & 0.74 & 1.6 & 2.58 & 3.69 & 0.49 & 0.31 & 3.81 & 3.2 & 0.25 \\
$\boldsymbol{T L}$ & 0.06 & 30.09 & 5.22 & 46.96 & 0.52 & 0.52 & 2.8 & 4.19 & 1.1 & 0.14 & 2.88 & 5.15 & 0.38 \\
$\boldsymbol{W W F L}$ & 0.41 & 27.05 & 7.17 & 41.83 & 1.15 & 0.87 & 3 & 3.81 & 0.85 & 0.2 & 3.81 & 9.46 & 0.38 \\
$\boldsymbol{O L} \boldsymbol{L}$ & 0.02 & 30.11 & 4.62 & 47.87 & 0.58 & 0.64 & 2.38 & 3.85 & 1.56 & 0.21 & 3.29 & 4.57 & 0.31 \\
\hline
\end{tabular}

\subsubsection{Land use probability transfer atlas}

According to formula (3) and formula (4), the CAMarkov model is calculated, and the land use state transfer map of each year is generated. According to the transfer probability matrix of this 4 years, the land use situation in 2024 is simulated and predicted. As shown in figure 4, figure 5, figure 6 .

Comparing the actual area of Qingzhen in 2020 with the predicted area of Qingzhen in 2024, the results showed that the spatial layout of land use has changed, the most obvious change is that the construction land has become more concentrated from scattered distribution; the transportation land is increased clearly.

Compared with the trend of land use change between 2016-2020 and 2016-2024, it is obvious that the area of agricultural land continues to decrease and the expansion rate of construction land is slower than that of the previous period. The prediction results are in line with the expectation of government control of construction land and improvement of land use level. 


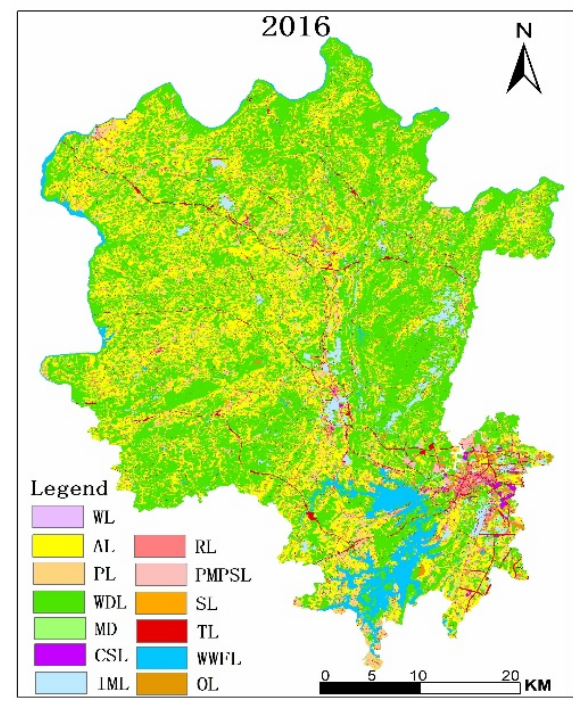

Fig 4. Qing zhen Land Use State by CA-Markov model (2016).

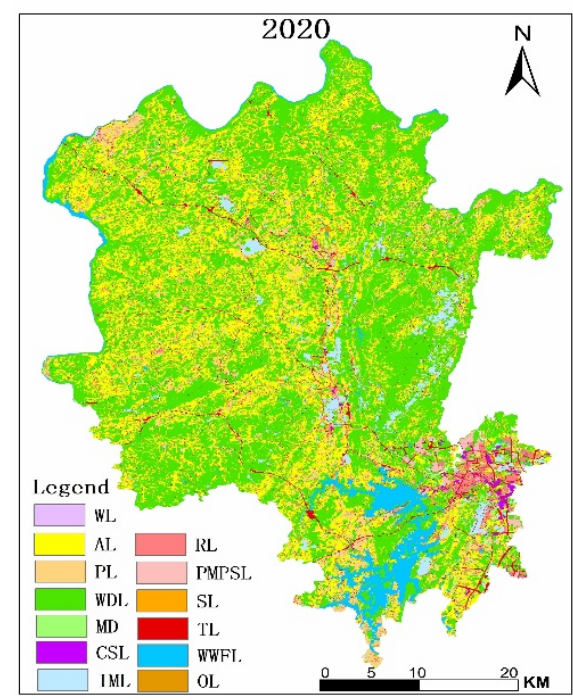

Fig 5. Actual situation of Qing zhen Land Use State (2020).

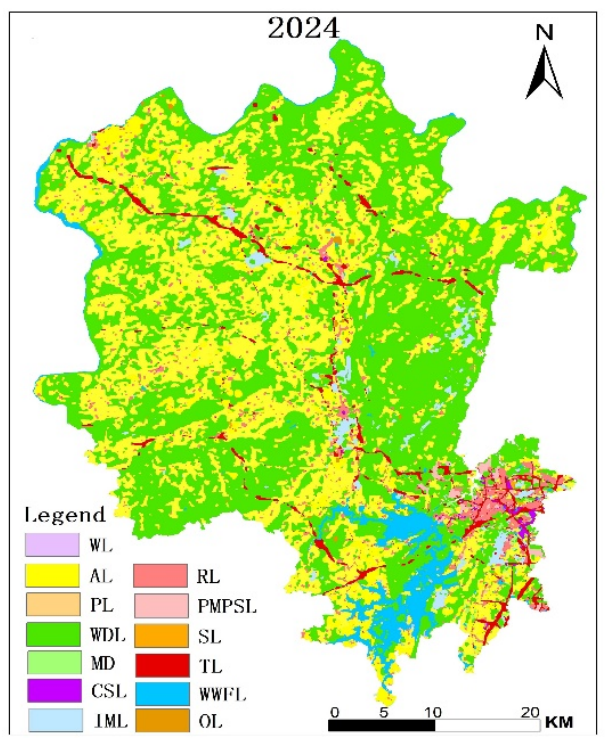

Fig 6. Prediction Situation of Qing zhen Land Use State (2024).

\section{Conclusions and discussions}

From the point of view of land use dynamics, the overall change rate was not violent; from the transfer of land type area, the proportion and direction of local class changes can be clearly obtained; from the CA-Markov prediction, agricultural land area continued to decrease, construction land expansion rate was slow, woodland, cultivated land area had increased. In general, the amount of cultivated land had reached the expected goal of the general land use plan of Qingzhen City (2006-2020). 52.86 hectares of construction land exceeded, so the construction land may need to be adjusted later.

According to the research results, the sustainable development suggestions were put forward: (1) centralization and urban-rural integration are the first choice of land use at present, to ensure better land distribution. (2) From the perspective of rural revitalization, it is necessary to contribute sustainable development of characteristic industries, and create new business cards for the city. (3) Pay attention to the quality of cultivated land and ensure food security. More information on prediction models would help us to establish a greater degree of accuracy on this matter.

\section{Acknowledgments}

This work was financially supported by the project of Guizhou Province Science and Technology Agency (Qiankehe Jichu [2018]1120, Qiankehe Zhicheng [2018]2776), and Science and Technology Foundation of Guizhou Provincial Department of Education (Grant No. KY[2016]084).

\section{References}

1. M.W.Wang.Analysis of Land Use Change in Wendeng District of Weihai City Based on Remote Sensing and GIS [D]. Shandong University of Science and Technology ,2020.

2. M.B.He .On the Application of "3S" Technology to Land Resource Management in China [J]. Resource Information and Engineering, 2017,32(01): 108+110.

3. J.L.Ding. T. Teiba. A Study on Information Extraction Method for Land Use/Cover Change in Cele Oasis Based [J]. Remote Sensing Study on the Geographical Environment of Yunnan ,2001(02):5459.

4. Y.X.Xiang. Analyis of Land Use Change and Landscape Patterns in Longling County, Yunnan Province [D]. Yunnan University ,2019.

5. L.X. Scenario Simulation of Land Use Change in Fuxian Lake Basin Based on CA-Markov Model [D]. Kunming University of Technology ,2017.

6. A.M.Dewa, Y.Yamaguchi.Using remote sensing and GIS to detect and monitor land use and land cover change in Dhaka Metropolitan of Bangladesh during 1960-2005[J]. Environmental Monitoring and Assessment,2009,150(1-4):237-249. 